\title{
An expectant role of Korean military hospital on impacted third molar research
}

\author{
Jeong-Kui Ku, DDS, MMSc, FIBCOMS \\ Department of Oral and Maxillofacial Surgery, Armed Forces Capital Hospital, Seongnam, Korea
}

Korean males are required to perform military service, and $92.0 \%$ of all enlisted Korean soldiers in 2018 were younger than 22 years. An impacted third molar, which occurs in about $70 \%$ of the total population ${ }^{1}$, is recommended for extraction before age 24 years to limit complications ${ }^{2}$. Therefore, most Korean soldiers are at the indicated age of surgical extraction. A third molar problem is the second most common dental emergency and results in a significant loss of duty time ${ }^{3}$. Soldiers, who could be stationed in areas with poor medical accessibility, are recommended to undergo preventive extraction even in the absence of symptoms. As a result, third molar patients represent the largest proportion of patients in the Department of Oral and Maxillofacial Surgery in a military hospital.

The statistics of Health Insurance Review and Assessment Service (HIRA), released in 2018, showed that $54.6 \%$ of total extractions in Korea were performed in 20- to 29-yearold people. In particular, the number of extractions in those aged 20 to 24 years was 54,001 fewer in males than females. (Fig. 1) As patients in military hospitals are not included in the statistics of HIRA, the number of extractions in military hospitals should be estimated. From 2013 to 2017, extraction surgeries in the Department of Oral and Maxillofacial Surgery of Armed Forces Capital Hospital accounted for 49.2\% of total surgical patients and 8,013 outpatients.

Most military patients are aged in the early twenties and have similar life patterns due to the nature of military service.

\footnotetext{
Jeong-Kui $\boldsymbol{K u}$

Department of Oral and Maxillofacial Surgery, Armed Forces Capital Hospital, 81 Saemaul-ro 117, Bundang-gu, Seongnam 13574, Korea TEL: +82-31-725-6184 FAX: +82-31-706-0987

E-mail:kujk123@gmail.com

ORCID: https://orcid.org/0000-0003-1192-7066

(c) This is an open-access article distributed under the terms of the Creative Commons Attribution Non-Commercial License (http://creativecommons.org/ licenses/by-nc/4.0/), which permits unrestricted non-commercial use, distribution, and reproduction in any medium, provided the original work is properly cited.

Copyright (C) 2020 The Korean Association of Oral and Maxillofacial Surgeons. All rights reserved.
}

In addition, conditions related to extraction surgery could be well controlled because all procedures - anesthesia, incision, ostectomy, odontomy, extraction, suture, dressing, hospitalization, stitch removal, and follow-up observation-are performed by the same military oral and maxillofacial surgeon. Since military hospitals are free of charge for all active duty patients, the surgeon can provide the best treatment options, such as bone graft for bony defect after extraction, without considering cost. Military patients are discharged when they achieve normal dietary intake and high physical activity. Therefore, the hospitalization period is relatively long compared with that in private hospitals. This long hospitalization allows military hospitals to monitor the longer-term condition of extraction patients, including food intake, pain, swelling, anxiety, and satisfactory healing process - which is difficult to achieve in private hospitals.

Although extraction surgery is a common operation in oral and maxillofacial surgery, military hospitals operate on an especially high proportion of third molar patients. Considering the nature of military hospitals, extraction patients could be provided ideal options and close monitoring that is not likely in private hospitals due to practical problems. Military research should be strictly reviewed and approved by the Armed Force Medical Command Institutional Review Board

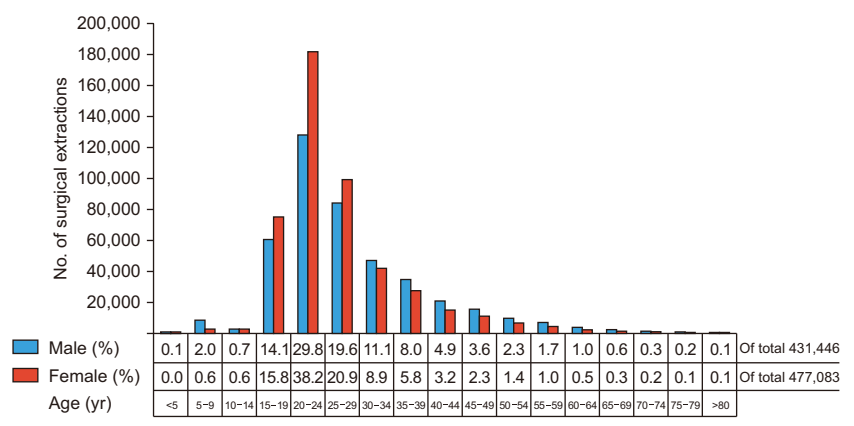

Fig. 1. Numbers of surgical extractions registered in the Health Insurance Review and Assessment Service in Korea during 2018. Jeong-Kui Ku: An expectant role of Korean military hospital on impacted third molar research. J Korean Assoc Oral Maxillofac Surg 2020 
since soldiers are regarded as an ethically vulnerable class, as military hospitals are suitable for third molar research. In conclusion, an expectant leading role in third molar research in Korean military hospitals will contribute to advancement of oral and maxillofacial surgery and to confidence around military medicine.

\section{Conflict of Interest}

No potential conflict of interest relevant to this article was reported.

\section{References}

1. Dodson TB, Susarla SM. Impacted wisdom teeth. BMJ Clin Evid 2014;2014:1302.

2. Blondeau F, Daniel NG. Extraction of impacted mandibular third molars: postoperative complications and their risk factors. J Can Dent Assoc 2007;73:325.

3. Chaffin J, Moss D. Review of current U.S. Army dental emergency rates. Mil Med 2008;173(1 Suppl):23-6.

How to cite this article: Ku JK. An expectant role of Korean military hospital on impacted third molar research. J Korean Assoc Oral Maxillofac Surg 2020;46:1-2. https://doi.org/10.5125/ jkaoms.2020.46.1.1 